\title{
The Application and Countermeasures of Sports Psychology in Physical Education Teaching
}

\author{
Shi Chengkun \\ Yunnan Technology and Business University, Yunnan, China, 651701
}

Keywords: sports psychology; physical education; the physical and mental health

\begin{abstract}
Physical education is an important part of school teaching to improve students' physical quality. It is of great practical significance to explore the application of physical education psychology in the current physical education teaching. In this paper, the present situation of sports psychology in physical education is discussed in detail, and some suggestions on the application of sports psychology in physical education are put forward. This paper aims to provide guidance for physical education teachers to improve their teaching effect and cultivate students' active participation in sports.
\end{abstract}

\section{Introduction}

Sports is an important part of education, which is an important criterion to measure the quality of education. In 1999, the third church was convened, and the central committee and the state council made clear that education should set up the guiding ideology of "health first". China has started to comprehensively promote the quality education, further deepening education reform. Through sports education, we can effectively enhance students' physical fitness level, stimulate students' interest in sports activities, and cultivate their awareness and habits of lifelong participation in physical exercise. The cultivated students not only have a strong physique, but also have certain sports knowledge. More importantly, through the cultivation of sports culture and the training of sports activities, the spirit of perseverance, hard work and spirit of solidarity and cooperation have been developed. However, the influence of psychological quality cannot be ignored. For physical education teachers, it is essential to strengthen the application of physical psychology in physical education. Pay attention to the students' psychology, and guide them in time, will make the students perform better.

\section{The Role of Sports Psychology in Physical Education}

\subsection{Regulate the students' emotional state.}

Emotional changes directly affect people's work, study and life. Good mood is an important condition for people to successfully engage in various activities and healthy life. The emotional change of middle school students plays an important role in improving teaching quality. The students' good emotional state is the key to the success of teaching, which can help students to explore their potential and play the technical level. Physical education is carried out in the outdoor dynamic, and the content of teaching materials is very different. The particularity of physical education makes students have special emotional state. If 1000 meters and above the middle-distance race, because of the weakness of the will to endurance exercise fear feeling. The particularity and the challenge of the project in the teaching of hurdling have led to fear. Rapid running and accurate jumping in the long jump cause emotional tension. Ball games are prone to extreme excitement. Physical examinations can also make students nervous. Once students have negative psychology, it is bound to affect the behavioral response, and cannot meet the requirements of technical action. Then there is a strong negative emotional state, which can lead to a vicious cycle. At this time, teachers should arouse attention and conduct psychological intervention, and find out the reasons for students' emotional state such as fear, tension and anxiety. 
physical education teachers should take advantage of the positive guidance of sports psychology and strengthen exercises appropriately, and learn to regulate emotional state, thus generating self-confidence.

\subsection{Improve students' attention.}

Attracting students' attention is the key to effective physical education. The teacher should pay attention to and observe the students at all times, and judge whether the students are distracted by their expressions, eyes and the quality of their movements. According to the specific situation of the students, the attention rules should be used to deal with them, and the teaching order should be arranged reasonably to improve the teaching effect. The attention of students in physical education class is easily distracted by the influence of the site, equipment and surrounding environment. The teacher should be invigorated, explain vivid image, demonstration strive to be perfect. At the same time, the students' attention is focused on physical education through short and flexible questions and answers, novel and interesting exercises, and flexible formation drills. Teachers should adopt various kinds of teaching methods, stimulate students' interest in learning, cultivate students' strong will quality, improve the students' attention, thus achieve the teaching demand, and get good teaching result.

\subsection{Arouse students' interest in sports.}

Sports teaching should pay attention to the cultivation of students' attitude and ability of lifelong sports, and improve students' understanding and understanding of the purpose and significance of sports. Sports interest is a kind of psychological tendency that people actively recognize, explore or participate in sports. It is an important driving force for sports and health knowledge and skills to promote physical and mental health. It is the foundation for the implementation of lifelong sports. The important way to improve teaching quality and effect is to stimulate students' interest in learning and to make students desire to learn. The rational use of sports psychology can achieve this goal and lay a good foundation for the smooth progress of the whole teaching process. When students are interested in sports. On the one hand, it can produce positive emotions, which can help the mastery of sports knowledge and skills, thus improving the learning quality. On the other hand, it also produces a pleasant emotional experience, so as to overcome the difficulties encountered and actively adhere to physical exercise. Teachers should also grasp the students' psychological characteristics to carry out teaching and stimulate students' interest in learning. For example, a beautiful environment can improve the excitability of the brain, and teachers can change the activity space to improve students' interest in sports. In physical education, there are various forms to mobilize students' interest. For example, interspersed with sports games, playing accompaniment music, group competitions and so on. On the basis of completing the teaching content, we will actively create a physical education situation and a pleasant and harmonious teaching atmosphere which can stimulate students' emotion and interest. Physical education teachers should help students to improve their understanding of the role of physical fitness, to guide and stimulate students' interest in sports.

\subsection{Master students' exercise load and keep healthy.}

In physical education, a certain amount of exercise load is applied to the body during the basic part of the exercise. This not only makes the muscles tense, but also makes the motor central nervous system highly excited. The end of PHYSICAL EDUCATION class is an important part of physical education. Many teachers only pay attention to the relaxation of the body in the organizing activities, and the teaching competition is often arranged to the final part of the basic part, so that students are still in the high excitement of physical and mental activities in the fast time. If the mental state of excitement cannot be properly eliminated, it will cause psychological fatigue, which will affect the study and rest of the day. Therefore, the end of physical education class should be taken seriously: First, lead the students to do relaxing physical exercises, so that the body is fully relaxed and then psychological relaxation; Second, instruct the students to use self-suggestion method, hint that their physical education is over, talk with the students about easy and pleasant 
topic, can not immediately arrange the after-school exercise. Thirdly, play a simple and interesting sports game, reduce the physical and mental stress, and gradually restore the students to the normal rhythm, which can reduce the impact on the follow-up study.

\section{The Problems Existing in the Process of Physical Education}

\subsection{The theory of sports psychology divorced from the practice of physical education.}

On the one hand, influenced by the current teaching system and teaching background, China's higher sports colleges pay more attention to the teaching results in the process of physical education. Although some teachers have realized the importance of introducing sports psychology into physical education, the evaluation of physical education has paid more attention to the teaching method. Physical education teachers have to sacrifice more scientific teaching process, finally make the sports psychology theory and physical education teaching practice dissociate. On the other hand, most physical education teachers do not understand the relevant content of sports psychology, and often focus on teaching effect in teaching process. Ignore the introduction and classroom application of the theory of sports psychology without applying relevant theory to classroom practice. In the end, students can only learn the operation skills and norms of the shallow level, without forming positive sports concepts and correct learning attitude, and the learning effect is greatly reduced.

\subsection{Lack of pertinence in teaching.}

Teaching in accordance with aptitude has always been a teaching concept advocated and valued by the educational circles. However, from the current situation of sports teaching in our country, the actual teaching and teaching of individual students have not been well implemented. However, the lack of pertinence is the serious problem in sports psychology education. First of all, from the point of view of the student body of physical education institutions, there are great differences between male and female students physically and mentally. It is difficult for all students to master relevant motor skills if the same, single teaching mode and teaching thinking are used to guide them. Secondly, due to the difference between male and female students, if there is a lack of attention to students' thoughts in the course of psychology teaching. It is difficult to cultivate students' correct sports mentality and positive sports spirit.

\subsection{The teaching philosophy ignored in the content of curriculum design.}

The most immediate purpose of the application of sports psychology is to make students develop active sports psychology and sports spirit. Finally, sublimation is the love of sports and the pursuit of sports. But at present, most physical education courses in colleges and universities are taught in the form of "teacher speaking, student listening" and "teacher demonstration, student imitation". Although the appearance of this kind of teaching has played a role of auxiliary teaching and active atmosphere to some extent, the teaching place and teaching thought are confined in the narrow space. And the course design content ignores the sports psychology teaching idea, does not pay attention to the student curriculum participation and the study enthusiasm. This has reduced the interest of physical education teaching, and weakened the ability of students to release pressure, pleasure and psychological burden through physical activity.

\section{The Strategies of Sports Psychology Applied to Physical Education}

\subsection{Realize the combination of sports psychology theory and practice teaching.}

The combination of teaching and practice is the first step in developing sports psychology. Only by applying sports psychology to specific teaching practice can we truly play the important role of this subject in teaching. For example, teachers can use the representation training method in the sports psychology theory to carry out practical teaching, to help students master various sports skills, and finally stimulate the enthusiasm of students to think positively. On the one hand, it USES the 
appearance thinking to guide students to perceive new things, to understand the sports spirit, and to effectively train students' ability to think independently. On the other hand, to increase the regularity of teaching, it is necessary to improve the students' training frequency, training quantity and related knowledge in depth and difficulty. In this way, students can learn and master knowledge and improve their understanding of sports. In physical education teaching, students' learning process is based on perception and practice, using the theory of sports psychology in the process of teachers in physical education teaching effective guidance, which can enrich the students' perception, and improve the teaching effect. However, it should be noted that in this process, the teacher's explanation should be accurate, and the language should be concise so as to avoid misunderstanding and influence the teaching activities.

\subsection{Apply the theory of sports psychology.}

The existence of individual difference will make different students have different cognition in accepting the same knowledge. Therefore, the application of sports psychology in physical education should pay attention to individual differences. On the one hand, based on the actual situation of students, combining the students' personality characteristics and personality differences, the teaching depth, breadth, progress and students' knowledge level and acceptance ability should be adjusted. On the other hand, pay attention to the physiological and psychological differences between male and female students and arrange different courses. Because male students are generally not interested in the collective practice of small load, single form and lack of novelty, they can provide some sports intensity and difficulty for them. For girls, it is possible to offer a relatively soft and suitable group exercise program for girls' physique. Only in the teaching of physical education, can we achieve better physical education effect.

\subsection{Pay attention to the reform and application of the form of physical education.}

The development and application of sports psychology in physical education is inseparable from the teaching form. The improvement of various multimedia equipment and information communication technology has provided strong support for the development of sports informatics, so as to ensure the popularization and application of sports psychology in physical education. We should pay attention to the reform of the form of physical education, and introduce the teaching mode of multimedia teaching. Through situational teaching method, project teaching method and other forms of teaching, sports psychology is integrated into the new teaching environment. In order to stimulate students' learning enthusiasm and motivation, they can help students master the sports skills effectively and form a positive sports mentality and sportsmanship. The application of sports psychology in physical education can stimulate students' interest in learning and motivate students to participate in physical exercise so as to improve the effect of physical education effectively. Therefore, universities should combine their own actual situation, based on students' development needs, strengthen the application of sports psychology in sports teaching, training students' lifelong sports idea, promote the development of sports teaching.

\section{Conclusion}

Sports psychology plays an incomparable role in the physical education of junior middle school, its scientific nature, effectiveness and feasibility, it is worth every physical education teacher to learn it, master it and use it. The use of good sports psychology in physical education enables students to study in a relaxed atmosphere. With good mental attitude, students can achieve comprehensive and healthy development of mind and body, so that teachers can achieve the goal of excellent teaching.

\section{References}

[1] Miyazoe, T, T. Anderson. The interaction equivalency theorem. Journal of Interactive Online Learning. (2010), p. 83 - 95 
[2] Caroline A Heaney, Natalie C. Walker. The challenges and opportunities of teaching sport and exercise psychology at a distance. Sport \& Exercise Psychology Review. (2014), p. 36 - 40

[3] Charles R. Graham. handbook of blended learning system: definition, current trends, and future direction. (2014), p. 89 - 93

[4] Miyazoe, T. LMS-based EFL blended instructional design: Empirical research on the sense of class community, learning styles, and online written interaction. (2013), p. 422 - 448

[5] Joanna Poon. Blended Learning: An Institutional Approach for Enhancing Students” Learning Experiences. Journal of Online Learning and Teaching. (2010), p. 448 - 469

[6] Wenger, Ferguson. A learning ecology model for blended learning from Sun Microsystems. The Handbook of Blended Learning. (2014), p. 65 - 68

[7] Florence Martin, Michele A Parker, Deborah F. Deale. Examining Interactivity in, Learning. (2012), p. 38 - 42 